\title{
Effects of Low-Energy-Density Microwave Treatment on Graphene/Polyvinyl Alcohol-Modified Poplar Veneer
}

\author{
Shuangshuang $\mathrm{Wu}^{1}$ and Wei $\mathrm{Xu}{ }^{1,2, *}$ \\ 1 College of Furnishings and Industrial Design, Nanjing Forestry University, Nanjing 210037, China; \\ wushuangshuang@njfu.edu.cn \\ 2 Co-Innovation Center of Efficient Processing and Utilization of Forest Resources, \\ Nanjing Forestry University, Nanjing 210037, China \\ * Correspondence: xuwei@njfu.edu.cn; Tel.: +86-025-8542-7459
}

check for updates

Citation: Wu, S.; Xu, W. Effects of Low-Energy-Density Microwave Treatment on Graphene/Polyvinyl Alcohol-Modified Poplar Veneer. Forests 2022, 13, 210. https: / / doi.org/10.3390/f13020210

Academic Editors: Edward Roszyk and Magdalena Broda

Received: 30 December 2021

Accepted: 27 January 2022

Published: 31 January 2022

Publisher's Note: MDPI stays neutral with regard to jurisdictional claims in published maps and institutional affiliations.

Copyright: (C) 2022 by the authors. Licensee MDPI, Basel, Switzerland. This article is an open access article distributed under the terms and conditions of the Creative Commons Attribution (CC BY) license (https:// creativecommons.org/licenses/by/ $4.0 /)$.

\begin{abstract}
The combination of natural wood and graphene can provide a new type of material with excellent mechanical properties and thermal conductivity. However, it is difficult for graphene to uniformly penetrate the wood due to the anisotropy of natural wood and the agglomeration of graphene. In this work, poplar veneer was treated with low-energy-density microwave to expand the entry pathways for the graphene steering liquid. The porosity, weight percent gain, and chromatic aberration were used to examine the impact of the microwave time and power. We tested the mechanical properties, thermal conductivity of the graphene/polyvinyl alcohol-modified poplar veneer to evaluate its properties. At the same time, SEM, XRD, and FT-IR were used to characterize its physical and chemical structure. The results showed that low-energy-density microwave treatment increased the weight percentage gain (WPG) and porosity without affecting the mechanical properties of the poplar veneer. The graphene-modified poplar veneer with the optimal overall performance was obtained by microwave treatment at $100 \%$ microwave power for $50 \mathrm{~s}$. Indeed, the microcharacterization also revealed that the microwave treatment mostly attacked the wood rays but had little effect on the materialized structure. Therefore, low-energy-density microwave treatment could be an energy-saving and efficient way to improve graphene-impregnated veneers.
\end{abstract}

Keywords: microwave treatment; poplar veneer; multilayer graphene; impregnation effect

\section{Introduction}

Traditional heating facilities, such as stoves, heaters, air conditioners, etc., generally cause severe environmental pollution, large amounts of wasted energy, uneven temperature distribution, discomfort among users, and high occupancy costs. Therefore, economic, energy-saving and comfortable floor heating technology has attracted people's attention. People have always used wood as a flooring material in bedrooms and living rooms. Due to the shortage of timber resources, more attention has been focused on fast-growing forestry. Fast-growing wood usually has a low density and poor mechanical strength, so it often appears in the form of a wood composite board that can be used as a floor heating surface material. It has several shortcomings including poor thermal conductivity, ranging from 0.04 to $0.4 \mathrm{~W} \cdot \mathrm{m}^{-1} \cdot \mathrm{K}^{-1}$, which is closely related to the species [1] and moisture content [2], and it suffers from dimensional instability caused by changes in the temperature and humidity. Modifying fast-growing wood to popularize its application for in-floor heating systems has a significant impact on protecting the environment and economically.

Owing to its high thermal conductivity $\left(\sim 4840-5300 \mathrm{~W} \cdot \mathrm{m}^{-1} \cdot \mathrm{K}^{-1}\right)$, good mechanical properties, high specific surface area, and unusual electronic properties (carrier mobility up to $200,000 \mathrm{~cm}^{2} \cdot \mathrm{V}^{-1} \cdot \mathrm{s}^{-1}$ ), graphene has attracted much scientific interest in various applications since its inception. Wu et al. (2021) prepared a high-strength wood/graphene three-dimensional conductive material by using the hot-press reduction method, which increased its mechanical strength to nearly twice that of raw wood just by adding $3 \mathrm{mg} \cdot \mathrm{mL}^{-1}$ 
of graphene oxide [3]. Lin et al. (2020) prepared a type of heat storage wood by using polyethylene glycol wrapped with graphene aerogel to vacuum impregnate the wood. The results showed that the addition of graphene aerogel effectively improved the thermal conductivity of the heat storage wood, which was up to $0.374 \mathrm{~W} \cdot \mathrm{m}^{-1} \cdot \mathrm{K}^{-1}$, that is, 2.74 times than before [4]. Zhang et al. (2019) made wood plastic composites (WPCs) from poplar wood fiber, polyethylene (PE), maleic anhydride grafted polyethylene (MPAPE), and graphene nanoplatelets (GNPs) by using a co-rotating twin-screw extruder. The results showed that when the content of GNPs increased to $12 \mathrm{wt} . \%$, the thermal conductivity of the WPCs increased by $258.9 \%$. They also highlighted that compared with graphite, the addition of graphene nanoplatelets had a more significant enhancement effect on the heat transfer due to the effective phonon diffusion in GNPs [5]. Therefore, it is now widely recognized that graphene can be used as a functional filler to effectively improve wood's mechanical properties and thermal conductivity. However, due to the strong $\pi-\pi$ interaction and van der Waals force between graphene nanosheets, graphene is prone to aggregation. When the dispersity of graphene in steeping solution is unsatisfactory, graphene will not work optimally. The functional modification of graphene is an effective way to improve the bonding performance between its interface and the matrix, mainly through modifying the edge plane or the remaining oxygen-containing functional groups during the preparation process [6]. Xu et al. (2013) used $\mathrm{SOCl}_{2}$ to reflux graphene oxide in a nitrogen atmosphere. They fixed the porphyrin ring on the surface of graphene oxide through covalent bond modification to obtain a stable dispersion of graphene oxide [7]. Salavagionel et al. (2009) used the esterification reaction between graphene oxide and polyvinyl alcohol (PVA) to modify graphene. They concluded that the covalent bond between the graphene laminate and PVA was responsible for significantly changing its crystallinity and thermal stability. Even more to the point, the reaction between the PVA and graphene was not sufficient, so the unreacted graphene oxide had to be removed by centrifugation and other treatments [8]. In addition, using PVA in the fast-growing area of wood modification has become a preferred green method to boost its additional features and enhance its commercial value in recent years. Subba Rao et al. (2019) fabricated a biodegradable and highly flexible transparent wood-polymer composite from poplar veneers and PVA considering the cost and environmental impact [9]. Therefore, PVA could assist graphene in modifying wood by acting as a connecting bridge between the graphene and the wood.

Improving the permeability of the graphene-modified substrates seems to be a more convenient method; that is, more space is established in the wood to enhance the impregnation effect. Microwave treatment is considered an effective method to improve the impregnation ability of timber. Under the irradiation of high-radiation microwaves, the moisture in the wood cells quickly vaporizes. As a result, it forms outwardly diffused vapor pressure, which acts on the cell walls, breaks through the weak links such as the pit membrane, and establishes a radial channel through which the liquid and steam can easily pass [10]. Achieving this goal requires a microwave energy density of $250 \sim 1200 \mathrm{MJ} \cdot \mathrm{m}^{-3}$, according to the physical properties and the initial moisture content of the wood [11]. The high-energy-density microwave (up to $1200 \mathrm{MJ} \cdot \mathrm{m}^{-3}$ ) can transform the wood into a highly porous and macro-cracked material, which significantly improves the impregnation effect of functional modifiers; however, it does extreme harm to the microstructure and decreases the mechanical properties. Therefore, obtaining better strength and dimensional stability than ordinary wood depends on the subsequent impregnation resin and densification treatment [12]. Although microwave treatment with low energy density $\left(250 \sim 350 \mathrm{MJ} \cdot \mathrm{m}^{-3}\right)$ does not significantly improve the material's permeability as well as high-energy-density microwave treatment, the density and strength of the wood is not substantially affected [13]. Therefore, it appears to be a more economical and environmentally-friendly treatment method for wood impregnation.

Therefore, this work focused on the effect of the low-energy-density microwave radiation and action time on graphene/PVA impregnated poplar veneer. The optimal microwave settings were determined by taking the mechanical properties and thermal 
conductivity of the graphene/PVA impregnated poplar veneer as evaluation indicators. Furthermore, the modified poplar veneer with the best performance was characterized to analyze the influence mechanism of the low-energy-density microwave treatment on the performance of graphene/PVA impregnated wood. This will help to promote the application of graphene/PVA impregnated veneer in wood flooring and the application of low-energy-density microwave in the wood impregnation modification process.

\section{Materials and Methods}

\subsection{Experimental Materials}

Poplar veneers (species: Populus tomentosa Carr., specification: $140 \mathrm{~mm} \times 140 \mathrm{~mm} \times 2 \mathrm{~mm}$, initial moisture content: $13.8 \%$ ) were provided by Dehua Tubao Decoration New Material Co., Ltd. (Deqing, China). The veneers were peeled from the poplar and have a density of $0.38 \mathrm{~kg} \cdot \mathrm{m}^{-3}$. The veneer's surface was clean and flat, without knots, cracks, and other defects. All the veneers were polished with 240-mesh sandpaper, and the dust was blown off with an ear-washing ball. The multilayer graphene powders were purchased from Suzhou Tanfeng Graphene Technology Co., Ltd. (Suzhou, China). The number of layers ranged between 6 and 10. Each layer was $5 \sim 50 \mu \mathrm{m}$ in diameter and 3.4 8 $\mathrm{nm}$ in thickness. Polyvinyl alcohol (PVA) (Mw $=88,000,87 \sim 89 \%$ hydrolyzed) was purchased from Nanjing Daguangming Chemical Reagent Co., Ltd. (Nanjing, China). Distilled water was homemade in the laboratory.

\subsection{Experimental Design}

Microwave treatment can improve the permeability of poplar veneers, which allows more steeping solutions to penetrate the poplar veneers. In order to explore the best microwave treatment process, a two-factor complete experiment was conducted to explore the influence of microwave treatment on the performance of the poplar veneers impregnated by multilayer graphene/polyvinyl alcohol (MG/PVA). The two main factors affecting the microwave treatment effect were microwave power $(70 \%, 85 \%$, and $100 \%$, equal to $250 \mathrm{MJ} \cdot \mathrm{m}^{-3}, 300 \mathrm{MJ} \cdot \mathrm{m}^{-3}, 350 \mathrm{MJ} \cdot \mathrm{m}^{-3}$, respectively) and microwave time $(20 \mathrm{~s}, 30 \mathrm{~s}, 50 \mathrm{~s}$, and $80 \mathrm{~s}$ ). The specific formula is shown in Table 1 . The experiment used untreated poplar veneer and poplar veneer impregnated by MG/PVA without microwave treatment as a control.

Table 1. The formula for a two-factor complete experiment.

\begin{tabular}{cccccc}
\hline Number & $\begin{array}{c}\text { Microwave } \\
\text { Time/s }\end{array}$ & $\begin{array}{c}\text { Microwave } \\
\text { Power/\% }\end{array}$ & Number & $\begin{array}{c}\text { Microwave } \\
\text { Time/s }\end{array}$ & $\begin{array}{c}\text { Microwave } \\
\text { Power/\% }\end{array}$ \\
\hline M-1 & & 70 & M-7 & & 70 \\
M-2 & 20 & 85 & M-8 & 50 & 85 \\
M-3 & & 100 & M-9 & & 100 \\
\hline M-4 & & 70 & M-10 & & 70 \\
M-5 & \multirow{2}{*}{30} & 85 & M-11 & 80 & 85 \\
M-6 & & 100 & M-12 & & 100 \\
\hline
\end{tabular}

\subsection{Preparation Process}

As shown in Figure 1, the preparation process included three main steps, microwave treatment, steeping solution preparation, and vacuum impregnation.

\subsubsection{Microwave Treatment}

Before microwave treatment, the veneers were put into a constant temperature and humidity chamber (DF-408, Defu Environment Test, Shanghai, China) with a temperature of $25^{\circ} \mathrm{C}$ and $60 \%$ air relative humidity (RH) until constant mass to ensure uniform moisture content. At the same time, the microwave chemical reactor (WBFY-201, Yuhua, Jiaxing, China) was preheated until the temperature at the bottom of the resonant cavity reached a stable level to reduce the influence on the heating rate of the test piece. Moreover, the 
veneers were microwave treated one by one and put in the same place each time. Lastly, the microwave-treated and the control samples were dried at $103{ }^{\circ} \mathrm{C}$ in a drying oven (DHG-9643BS-III, CIMO, Shanghai, China) until they reached a constant weight.

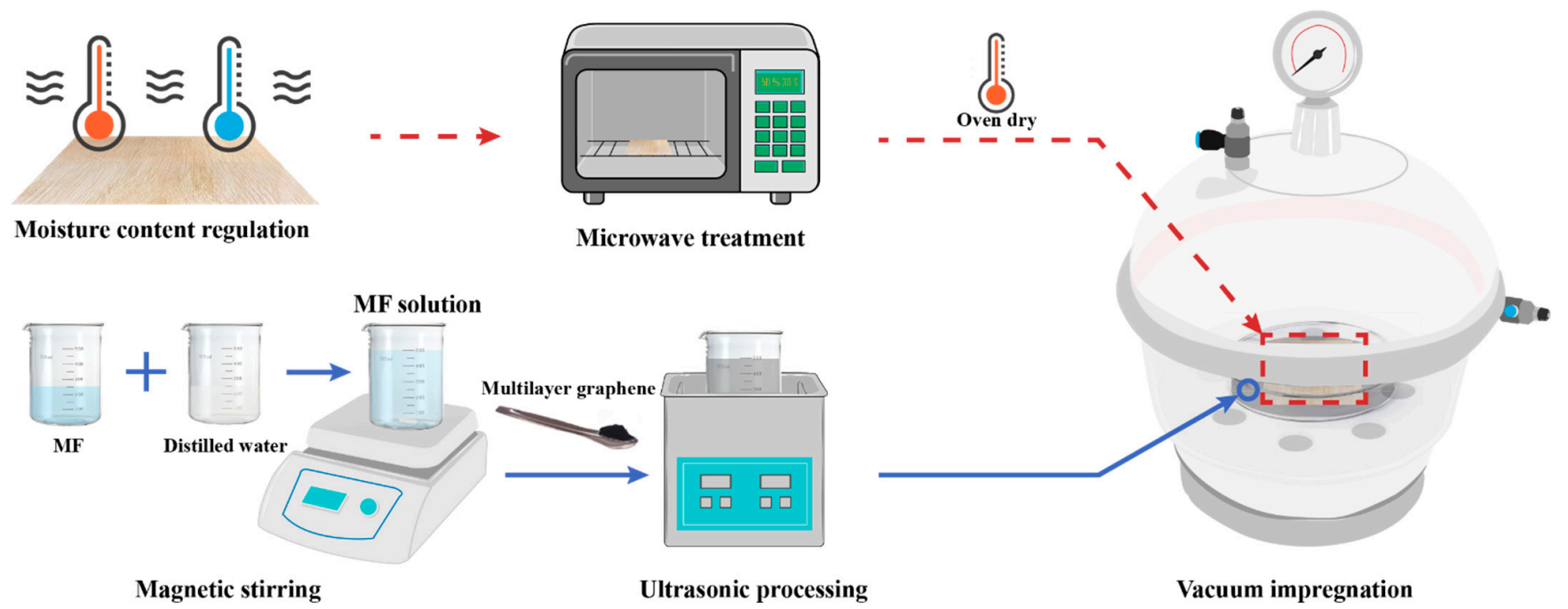

Figure 1. The preparation of the MG/PVA impregnated poplar veneers with microwave treatment.

\subsubsection{Steeping Solution Preparation}

A total of $90 \mathrm{~g}$ of steeping solution was used for each veneer. The solution was made from PVA and distilled water at a ratio of 1:9 by magnetic stirring for $2 \mathrm{~h}$. Soon thereafter, the multilayer graphene was added into the PVA solution at $2 \mathrm{wt}$ \% of the PVA solid content. In addition, this formula was better than that used in the authors' previous work [14]. In order to improve the dispersion of the multilayer graphene, the steeping solution underwent $400 \mathrm{~W}$ ultrasonic processing (BILON-500, BILON, Shanghai, China) for $20 \mathrm{~min}$ before use.

\subsubsection{Vacuum Impregnation}

All veneers were presoaked for 30 min at atmospheric pressure before vacuum impregnation to avoid the poplar veneers floating above the steeping solution. Then, the poplar veneers were impregnated in the vacuum drier (PC-3, Shanghai Sanshe Industry Co., Ltd., Shanghai, China) for $60 \mathrm{~min}$ at 14 psi and kept for $30 \mathrm{~min}$ under normal pressure. Finally, the impregnated veneers were treated again following the above drying method.

\subsection{Measurements and Characterizations}

\subsubsection{Data Analysis}

In order to explore the influence of microwave power and microwave time on the impregnation effect of MG/PVA modified poplar veneer, the respective main effects of microwave power and microwave time and the interaction between them were examined by a two-way analysis of variance (ANOVA). Microwave time and microwave power were considered as the independent variables and the dependent variables were porosity and the WPG. All data analyses were performed at the 5\% significance level by IBM SPSS Statistics (Version 26, International Business Machines Corp., Armonk, NY, USA).

Error bars were used to represent the amount of uncertainty in the measured data when testing porosity, weight percent gain, mechanical properties, and thermal conductivity. In addition, error bars were the standard deviation of the measured data.

\subsubsection{Porosity}

The microwave treatment used the synergistic effect of water and heat to soften the wood components and this combined with the internal and external pressure difference to 
destroy the wood microstructure and improve the wood permeability. The porosities of the raw veneer (RV) and the veneer with different microwave treatments (MV) were measured to explore the influence of microwave treatment on the permeability of the poplar veneers according to a simple weighing method $[15,16]$. The test was repeated 5 times within each microwave treatment groups. The samples were cut into regular square slices (specification: $40 \mathrm{~mm} \times 40 \mathrm{~mm} \times 2 \mathrm{~mm}$ ), and their weight was measured by an electronic balance (TD5002C, Tianma, Nanjing, China). The apparent density was calculated according to the following Equation (1):

$$
\text { Apparent density }=\frac{m_{0}}{l \times w \times h}
$$

where $m_{0}$ is the initial quality of the absolutely dried veneer, $g ; l, w, h$ are the length, width, and height of the veneer, $\mathrm{cm}$.

Then, the veneers were immersed into isopropanol until they reached saturation. The weight of the isopropanol-filled veneers was measured again. The porosity was calculated according to Equation (2):

$$
\text { Porosity }=\frac{m_{1}-m_{0}}{\rho_{\text {isopropanol }} \times(l \times w \times h)} \times 100 \%
$$

where $m_{1}$ is the quality of the veneer fully immersed in isopropanol, $\mathrm{g}$; $\rho_{\text {isopropanol }}$ is the density of isopropanol, $0.7863 \mathrm{~g} \cdot \mathrm{cm}^{-3}$.

\subsubsection{Weight Percent Gain (WPG)}

The weight percent gain (WPG) is a simple and intuitive method to characterize the adequacy of the impregnation. Both the untreated veneer and the modified veneer were oven-dried at $103{ }^{\circ} \mathrm{C}$ until they reached constant weight. The WPG for each veneer was calculated according to the following Equation (3):

$$
\mathrm{WPG}=\frac{m_{1}-m_{0}}{m_{0}} \times 100 \%
$$

where $m_{0}$ is the initial quality of the absolutely dried veneer, $g ; m_{1}$ is the quality of the veneer impregnated with MG/PVA, g.

Likewise, the test was repeated 5 times within each microwave treatment groups.

\subsubsection{Chromatic Aberration}

The chromatic aberration was used to examine the impregnation effect by comparing the color difference between a graphene-modified veneer and an untreated one. Firstly, five points were randomly selected and marked on each sample. Then, five groups of data were obtained by a colorimeter (HP-2126, Zhuhai Tianchuang Instrument Co., Ltd., Zhuhai, China), and the average values of $L^{*}, a^{*}, b^{*}$ were recorded. The $\Delta E^{*}$ value for each impregnated veneer was calculated by using the following Equation (4):

$$
\Delta E^{*}=\left[\left(L_{1}^{*}-L_{0}^{*}\right)^{2}+\left(a_{1}^{*}-a_{0}^{*}\right)^{2}+\left(b_{1}^{*}-b_{0}^{*}\right)^{2}\right]^{1 / 2}
$$

where $\Delta E^{*}$ is the comprehensive evaluation index of the color difference, $L_{1}^{*}$ is the lightness of the graphene-modified veneer, $a_{1}^{*}$ is the change in color from red to green of the graphenemodified veneer, $b_{1}^{*}$ is the change in color from yellow to blue of the graphene-modified veneer. Similarly, $L_{0}^{*}, a_{0}^{*}$, and $b_{0}^{*}$ are the corresponding values of the untreated poplar.

\subsubsection{Mechanical Properties Test}

A precision electronic, mechanical testing machine (AG-IC, SHIADAZU, Kyoto, Japan) was used to measure the mechanical properties of the impregnated veneers according to GB/T 17657-2013 [17]. The tensile rate was $1 \mathrm{~mm} \cdot \mathrm{min}^{-1}$, and the maximum load was $10,000 \mathrm{~N}$. 
The Shore-D hardness tester (LX-D, Xi Jing, Wuxi, China) was used to measure the hardness of wood according to the ASTM D2240 (2010) standard [18,19]. A $5 \mathrm{~kg}$ load was used as the weight to determine the hardness. Each sample was tested five times at different points, and the final result was taken as the average value.

\subsubsection{Thermal Conductivity}

Based on the steady-state flat plate method, a thermal conductivity analyzer (YBF-4, Dahua, Hangzhou, China) was used to measure the thermal conductivity of raw veneers $(\mathrm{RV})$, impregnated veneers that were not treated by microwave (RV-MP), and impregnated veneers that had been treated by microwave (MV-MP). The thermal conductivity value $\left(\lambda, \mathrm{W} \cdot \mathrm{m}^{-1} \cdot \mathrm{K}^{-1}\right)$ was calculated according to the following Equation (5):

$$
\lambda=\left.m c \frac{\Delta T}{\Delta t}\right|_{T=T_{2}} \bullet \frac{h}{T_{1}-T_{2}} \bullet \frac{1}{\pi R^{2}}
$$

where $m$ is the weight of a copper heat sink, $\mathrm{kg} ; \mathrm{c}$ is the heat capacity of a copper heat sink, $385 \mathrm{~J} \cdot \mathrm{kg}^{-1} \cdot \mathrm{K} ;\left.\frac{\Delta T}{\Delta t}\right|_{T=T_{2}}$ is the heat dissipation rate of a copper heat sink at $T_{2}, \mathrm{~K} \cdot \mathrm{s}^{-1} ; h$ is the thickness of tested veneers, $\mathrm{m} ; T_{1}$ is the temperature of the upper copper heat sink, $\mathrm{K} ; T_{2}$ is the temperature of the lower copper heat sink, $\mathrm{K} ; T_{1}-T_{2}$ is the temperature difference between the upper and lower copper heat sinks, $\mathrm{K} ; \pi R^{2}$ is the area of the copper heat sink, $\mathrm{m}^{2}, 0.0133 \mathrm{~m}^{2}$. In addition, the sample with the optimal thermal conductivity was marked as MV-OS, and the sample with the worst thermal conductivity was marked as MV-WS.

\subsubsection{Scanning Electron Microscope (SEM)}

The Scanning Electron Microscope (Quanta 200, FEI, MA, USA) was used to observe the effect of microwave treatment on the MG/PVA impregnated veneers. MV-OS and MV-WS cross-sections were cut and observed, and compared to the RV and RV-MP.

\subsubsection{X-ray Diffraction (XRD)}

In order to investigate the influence of the low-energy-density microwave treatment on the structure of poplar veneer, the crystallinity of MV-OS, RV, and RV-MP powders were characterized by an X-ray diffractometer (Ultima IV, Rigaku, Tokyo, Japan). The samples were all ground to 200-mesh powders using a grinder instrument (DE-100g, Hongjingtian, Jinhua, China). Then, the dry sample powder was put into the slide groove until it was flush with the surface of the slide. The XRD scanning was performed in the range from $5^{\circ}$ to $40^{\circ}$, and the target speed was $2\left(^{\circ}\right) \cdot \mathrm{min}^{-1}$.

All the tests on the samples were repeated three times, and the error was within $5.0 \%$.

\subsubsection{Fourier Infrared Spectroscopy (FT-IR)}

The MV-OS, RV, and RV-MP powders were tested on a VERTEX $80 \mathrm{~V}$ instrument (Bruker, MA, USA) to study the effect of low-energy-density microwave treatment on the chemical composition. All the samples were ground to 200-mesh powders using a grinder instrument (DE-100g, Hongjingtian, Jinhua, China). The resolution and the wave range were $4 \mathrm{~cm}^{-1}$ and $4000-400 \mathrm{~cm}^{-1}$, respectively.

All the tests on the samples were repeated three times, and the error was within $5.0 \%$.

\section{Results and Discussion}

\subsection{Microwave Treatment Effects on the Degree of Impregnation}

3.1.1. Effect of Microwave Treatment on Porosity and Weight Percent Gain (WPG)

Porosity can characterize the effect of the microwave treatment on the wood permeability, and the weight percent gain (WPG) is one of the essential indicators of the wood impregnation effect. In order to understand the auxo-action of the microwave power and time on graphene's impregnation of the wood, the relation between the porosity and WPG was considered. 
Figure 2 reveals the effect of low-energy-density microwave treatment on the porosity and weight percent gain (WPG). Compared with the control group, whose porosity was $54.47 \pm 1.12 \%$, all veneers treated by different combinations of low-energy-density microwave treatment showed an increase in porosity of $8.6 \% \sim 31.4 \%$. The porosity increased slowly over time at $70 \%$ and $85 \%$ microwave power, while at $100 \%$ microwave power, it increased quickly until reaching the peak in $50 \mathrm{~s}$, and then it dropped. At the same microwave time, the porosity increased with the increase in microwave power. The change in porosity primarily resulted from the fact that the longer microwave time and higher microwave power brought more energy and heat, so that more and more moisture escaped, in the form of steam, from the inside of the veneer, which may enlarge the luminal space or create new cracks. It has been reported that the airflow can pass through both the inter tracheid-bordered pits and horizontally-aligned rays, which could improve the porosity [20]. Indeed, we also found that when microwave energy and heat accumulate to a certain extent, even with low-energy-density microwave irradiation, the veneer's surface will be carbonized. This may be why the growth rate of the porosity slowed down or decreased.

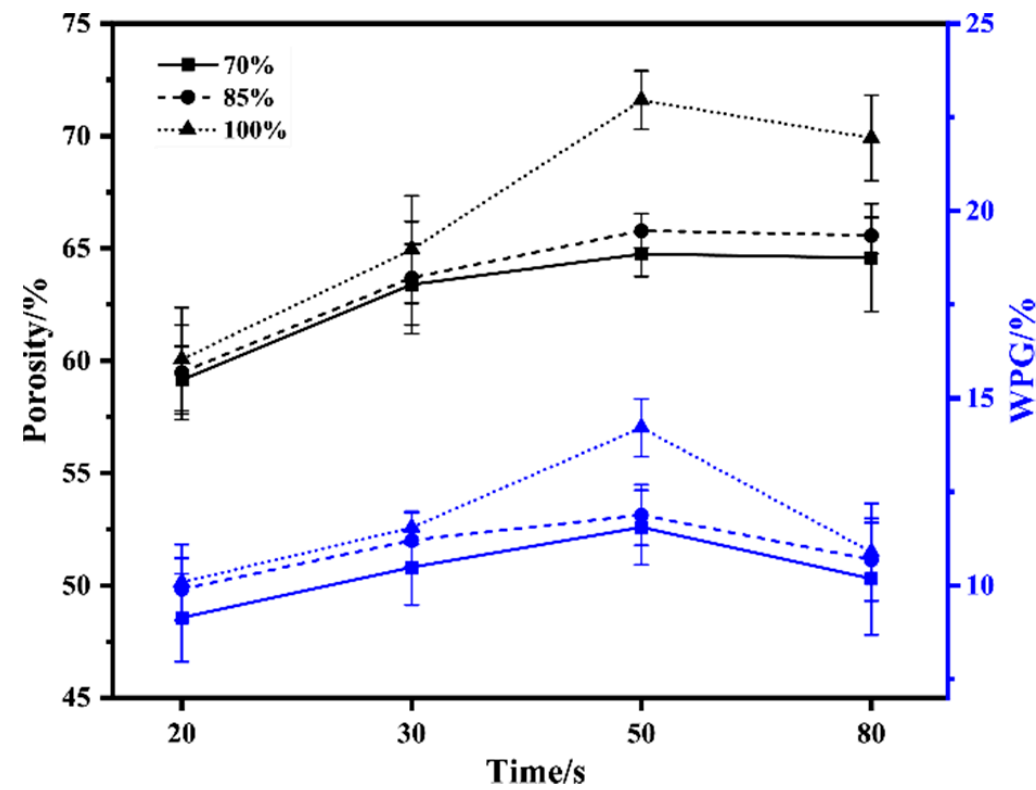

Figure 2. Effect of microwave treatment on the porosity.

The WPG showed a trend of first increasing and then decreasing, reaching the maximum at $50 \mathrm{~s}$, even with different microwave power. Overall, the trend in the change of the WPG is similar to that of the porosity. Meanwhile, the WPG of all samples was higher than the MG/PVA modified veneer, whose WPG was $7.58 \pm 0.4 \%$. This change was in line with the previous conjecture in the relevant literature that microwave treatment could enhance the penetration of preservatives [21].

The results of the between-subjects effects are shown in Table 2. Firstly, they indicated that the interaction between the microwave power and time had no significant effect on the porosity and the WPG. Then, we analyzed the results for the main effects of the two independent variables. Microwave power $(F=4.52, p<0.05)$ had a significant effect on porosity, and microwave time $(F=11.012, p<0.001)$ had a highly significant effect on porosity. At the same time, both microwave power $(F=5.146, p<0.01)$ and microwave time $(F=63.332, p<0.001)$ had a highly significant effect on the WPG. All data passed the test for homogeneity of variance. 
Table 2. The tests for between-subject effects.

\begin{tabular}{|c|c|c|c|c|c|c|c|c|c|c|}
\hline \multirow{2}{*}{ Source } & \multicolumn{5}{|c|}{ Dependent Variable: Porosity } & \multicolumn{5}{|c|}{ Dependent Variable: WPG } \\
\hline & $\begin{array}{l}\text { Type III Sum } \\
\text { of Squares }\end{array}$ & df & $\begin{array}{l}\text { Mean } \\
\text { Square }\end{array}$ & $F$ & Sig. & $\begin{array}{l}\text { Type III Sum } \\
\text { of Squares }\end{array}$ & df & $\begin{array}{l}\text { Mean } \\
\text { Square }\end{array}$ & $F$ & Sig. \\
\hline Microwave power & 179.684 & 2 & 89.842 & 4.518 & 0.016 & 28.755 & 2 & 14.377 & 5.146 & 0.009 \\
\hline Microwave time & 657.003 & 3 & 219.001 & 11.012 & 0.000 & 530.862 & 3 & 176.954 & 63.332 & 0.000 \\
\hline $\begin{array}{l}\text { Microwave power } \\
\times \text { microwave time }\end{array}$ & 97.856 & 6 & 16.309 & 0.820 & 0.560 & 13.936 & 6 & 2.323 & 0.831 & 0.552 \\
\hline Error & 954.557 & 48 & 19.887 & & & 134.115 & 48 & 2.794 & & \\
\hline Total & $248,761.396$ & 60 & & & & $20,110.965$ & 60 & & & \\
\hline
\end{tabular}

"Microwave power $\times$ microwave time" means the interaction between the two factors.

\subsubsection{Effect of Microwave Treatment on Chromatic Aberration}

Figure 3 shows the change in the MG/PVA modified veneers with different microwave treatments. In previous work, we learned that PVA does not affect the color difference, so the $\Delta E^{*}$ of the treated veneers could be used as a direct characterization method. Moreover, it was easy to see that the darker the color of the veneers impregnated with the same concentration of MG/PVA steeping solution, the more adequate the impregnation effect. In addition, all the $\Delta E^{*}$ were obtained by comparison with untreated veneer.

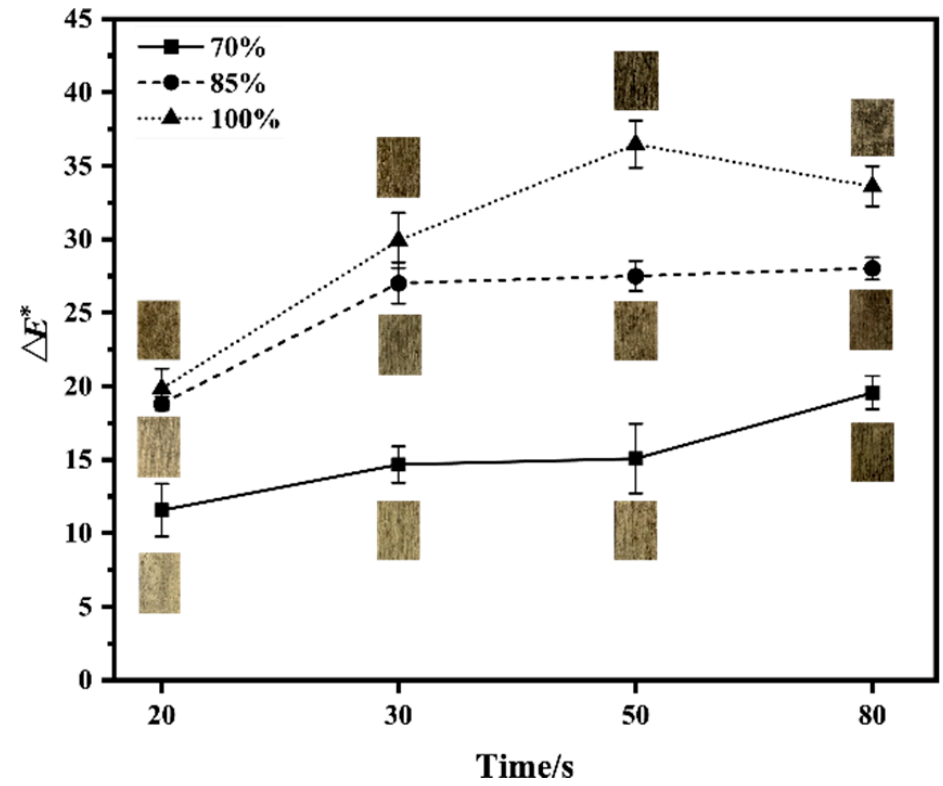

Figure 3. Effect of microwave treatment on chromatic aberration.

The picture showed that the stronger the microwave power, the greater the chromatic aberration between the modified and untreated veneers. At the same time, with the increase in the microwave time, the chromatic aberration showed an upward trend with a variable rate, except for the veneer treated by $100 \%$ microwave power for $80 \mathrm{~s}$. For modified veneers processed by $70 \%$ microwave power, there was no significant improvement between $20 \mathrm{~s}$ to $50 \mathrm{~s}$. In comparison, there was a significant change within 20 30 s for modified veneers processed by $85 \%$ and $100 \%$ microwave power. At the same time, the $\Delta E^{*}$ remained smooth after $30 \mathrm{~s}$ at $85 \%$ microwave power, while the $\Delta E^{*}$ continued to rise until it reached the peak in $50 \mathrm{~s}$ and then began to fall at $100 \%$ microwave power. In general, the chromatic aberration was most apparent when the $100 \%$ power was used for $50 \mathrm{~s}$, indicating that the impregnation effect was the most sufficient, which was consistent with the above results. 


\subsection{Performance of the $M V-M P$}

\subsubsection{Mechanical Properties}

Figure 4 displays the tensile strength and Young's modulus of the microwave-treated veneers. It could be seen from Figure $4 a$, $c$ that microwave treatment with low energy density had little effect on the tensile strength and Young's modulus of veneers. The untreated veneer was taken as a control, whose tensile strength and Young's modulus were $64.58 \pm 2.22 \mathrm{MPa}$ and $2615.56 \pm 9.41 \mathrm{MPa}$, respectively. After microwave treatment, most veneers showed better tensile strength, ranging from 64.01 71.69 MPa and better Young's modulus, ranging from 2485.20 2961.00 MPa. Combined with the above porosity data, it can be summarized that low-energy-density microwave treatment not only improves the permeability of poplar veneer, but also prevents the mechanical properties of the veneer from decreasing significantly. Therefore, it is suitable for treatment before veneer impregnation [22]. Both the tensile strength and Young's modulus improved with microwave power. In contrast, at the same microwave power, the extension of microwave time had no obvious influence on the mechanical properties.
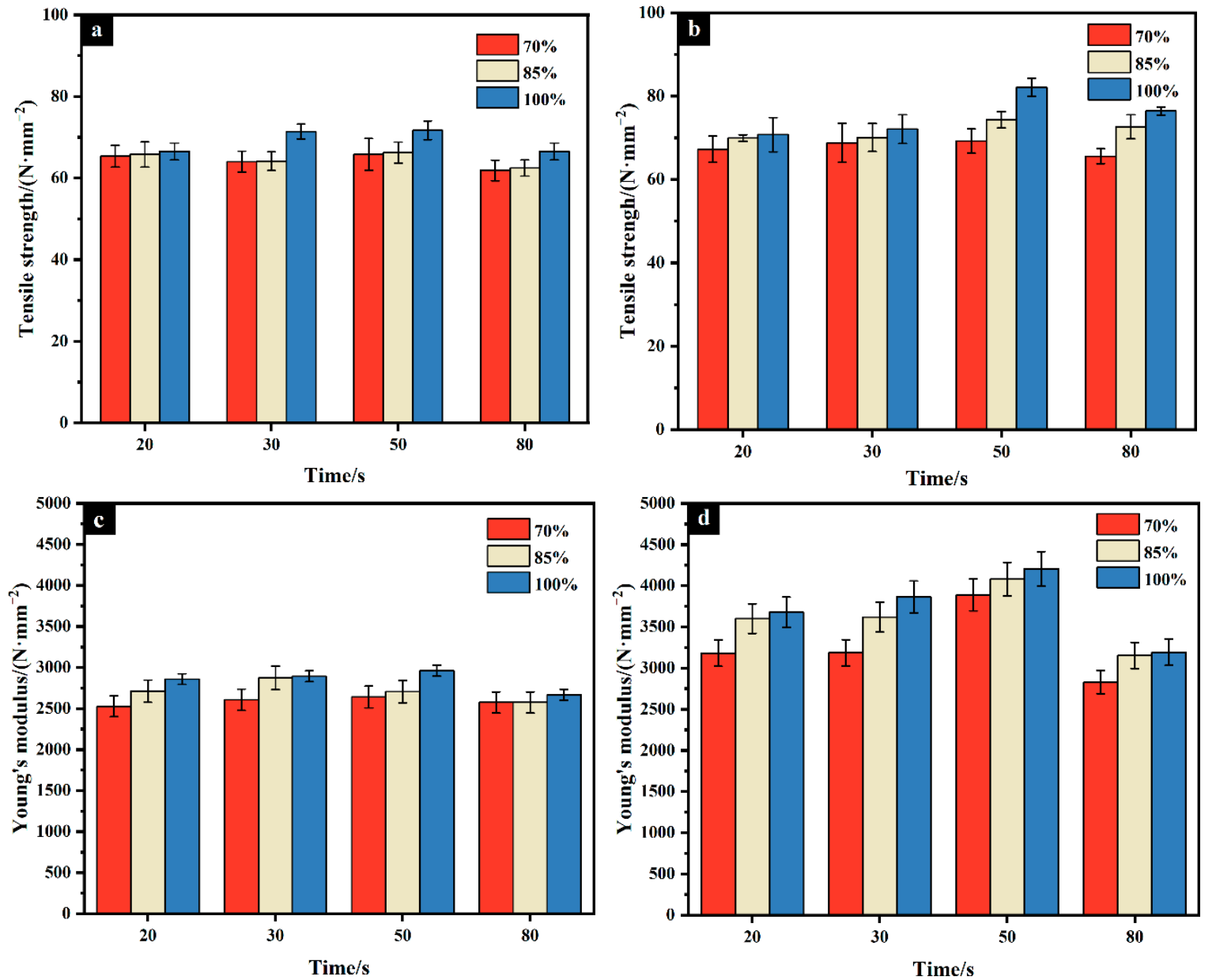

Figure 4. Effect of microwave treatment on the mechanical properties (a,c-the tensile strength and Young's modulus of veneers without impregnation, $\mathbf{b}, \mathbf{d}$ - the tensile strength and Young's modulus of impregnated veneers).

As shown in Figure $4 \mathrm{~b}, \mathrm{~d}$, both the tensile strength and Young's modulus showed the same trend as the WPG. A comparison of the untreated veneer impregnated with MG/PVA, whose tensile strength was $68.66 \pm 1.73 \mathrm{MPa}$ and $3386.69 \pm 9.45 \mathrm{MPa}$, showed that most modified veneers had enhanced tensile strength and Young's modulus, which were increased by $1.8 \% \sim 19.6 \%$ and $6.5 \% \sim 24.4 \%$, respectively. Besides, we found that 
both veneers with a lower microwave power percentage and short processing time and those with a long processing time did not achieve the desired optimization effect. This phenomenon might be because the passage for a large amount of MG/PVA fluid cannot be completely opened under the conditions of short time and low power, even though the microwave has increased the porosity and WPG [23]. As a result, most graphene was deposited on the surface, affecting its mechanical properties. On the other hand, as the microwave processing time was prolonged, the veneers were highly likely to be partially carbonized, which also has a certain impact on the mechanical properties. As summarized in the previous literature, microwave treatment can efficiently improve the impregnation effect, but only by selecting the appropriate power and time [24].

Additionally, the hardness of the modified veneers was tested to clarify its ability to resist rigid materials when being pressed and to understand the technological issues in the machining process. Figure 5 shows the change in the Shore-D hardness of the modified veneers. Compared with the untreated veneer, whose Shore-D hardness was 46.0, the Shore-D hardness of all modified veneers was improved, ranging from 51.2 to 59.6. Although the hardness was improved a bit, it was still at the stage where the hardness was the same as soft plastic. This means that the improvement in the hardness would not affect the machining of the modified veneers. In addition, we also found that the hardness kept increasing until the microwave time reached $50 \mathrm{~s}$ and then dropped at the same microwave power. At the same time, there was no consistent trend in the change in Shore-D hardness.

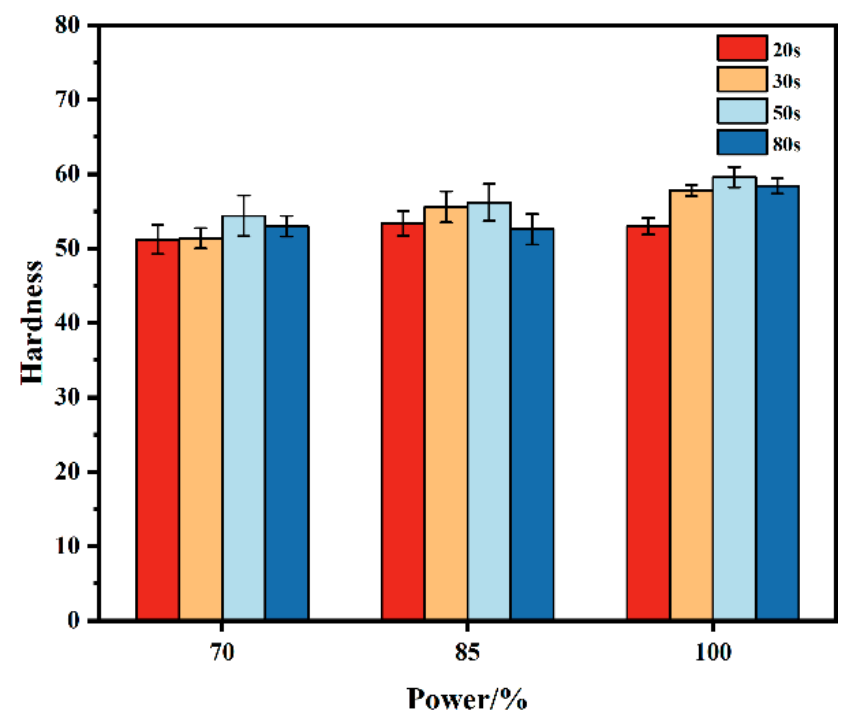

Figure 5. The effect of microwave treatment on the hardness.

\subsubsection{Thermal Conductivity}

The optimal technological parameters were selected by taking thermal conductivity as the evaluation indicator. As shown in Figure 6, all the veneers impregnated with MG/PVA had higher thermal conductivity than the raw veneer. Except for the samples treated by $70 \%$ microwave power for $20 \mathrm{~s}$, the other impregnated veneers' thermal conductivity with microwave treatment was higher than that of RV-MP. From the line chart in Figure 6, it was found that the thermal conductivity first increased and then decreased when the microwave power was the same. Similarly, it reached its maximum at $50 \mathrm{~s}$, consistent with the WPG. Simultaneously, the thermal conductivity rose continuously and out of proportion with the increase in microwave power. This also verified that the microwave treatment expanded the original cell cavities or created new cracks for the graphene impregnation liquid to enter the veneer, thus improving thermal conductivity [25]. 


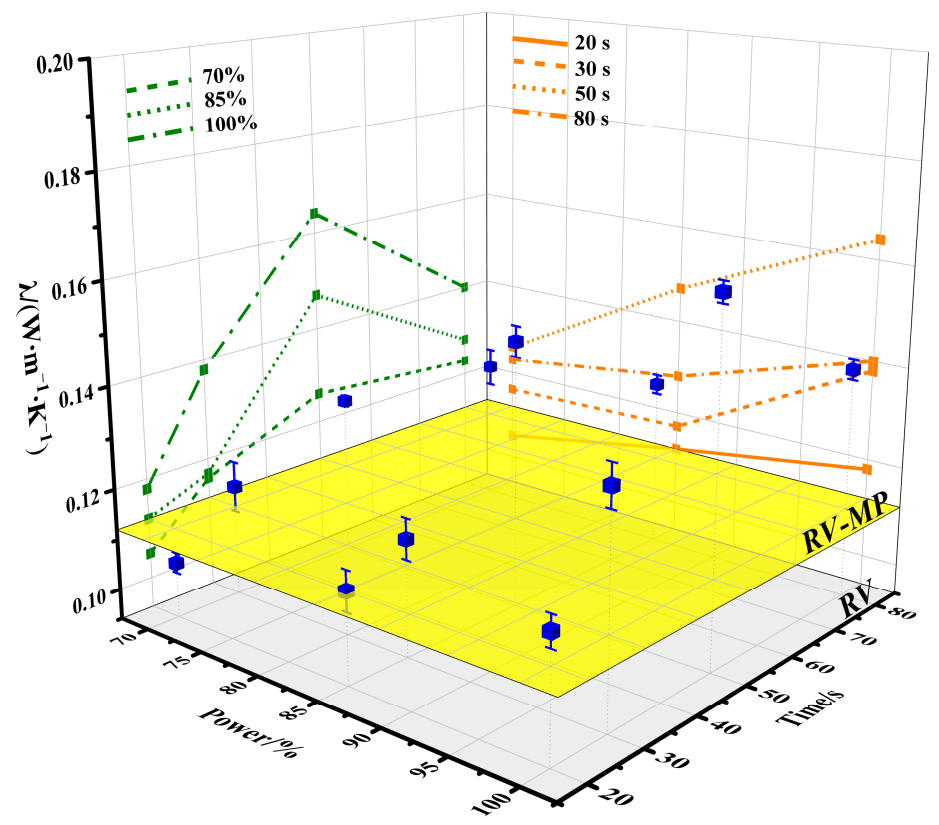

Figure 6. The thermal conductivity of MV-MP (RV and RV-MP as control groups).

Besides, the thermal conductivity dropped rapidly after $50 \mathrm{~s}$, which might be caused by the graphene's agglomeration. Previous research has shown that graphene's agglomeration severely influences its performance [26]. Another contributing factor is the carbonized surface of the veneer. At long microwave time and high microwave power, the veneer exhibited local carbonization due to uneven heating, resulting in a fragile and brittle wooden structure. Therefore, the impregnation process was affected, leading to a decrease in the modified veneer's properties. Although this conjecture has not been verified, during the investigation of the structural changes in wood ceramics, Qian et al. (2004) found that its crystal form changed with the increase in carbonization temperature. Due to the volume shrinkage, some pores might be closed, causing the gathering of the porosity to slow down or the porosity to decrease [27]. Therefore, further analysis of the materialized structure was conducted to reveal the mechanism.

\subsection{SEM Analysis}

Figure 7 shows the cross-sectional electron micrograph of untreated poplar veneer (RV), untreated veneer impregnated with MG/PVA (RV-MP), and the microwave treatment veneer impregnated with MG/PVA (MV-WS and MV-OS). It can be seen from Figure 7a that the untreated poplar veneer had apparent linear wood rays, which are composed of a large number of axial parenchyma cells. Compared with RV, RV-MP still retained the linear wood rays, and the catheter structure showed little change, as shown in Figure $7 \mathrm{~b}$,f. At the same time, the cell walls became smooth due to the immersion. In Figure 7c, there are still apparent wood rays in MV-WS, although the wood rays are distorted and wider cracks appear in the axial parenchyma cells, which can be seen in Figure 7g. This is closely related to the airflow generated by the rapid transpiration of internal moisture under the microwave action, which attacks the axial parenchyma cells with the weakest structure [28]. Therefore, theoretically there were more paths inside the veneer for the graphene/PVA solution to enter after the microwave treatment. However, the degree of impregnation of MV-WS was not significantly improved compared with RV-MP. This phenomenon mainly stems from the fact that the microwave treatment increased the internal cracks, but it was insufficient to open the channel outward. Compared with MV-WS, with the increase in microwave power and treatment time, Figure 7d,h show that MV-OS did not have clear wood rays because the axial parenchyma cells were filled. Compared with RV-MP, most of the cells were fully impregnated, and even parts of the ducts were also filled, indicating 
that proper microwave treatment can provide more space for graphene to enter the wood substrate. Thereby, the performance of the modified poplar veneer was improved. The SEM analysis showed that the appropriate microwave treatment helped the graphene steeping solution to fully enter the poplar veneer's interior, thereby establishing a continuous heat transfer channel and improving its thermal conductivity. At the same time, the initially collapsed cell cavity was filled with heat-cured steeping solution and became plump, which promoted the improvement in the mechanical properties.

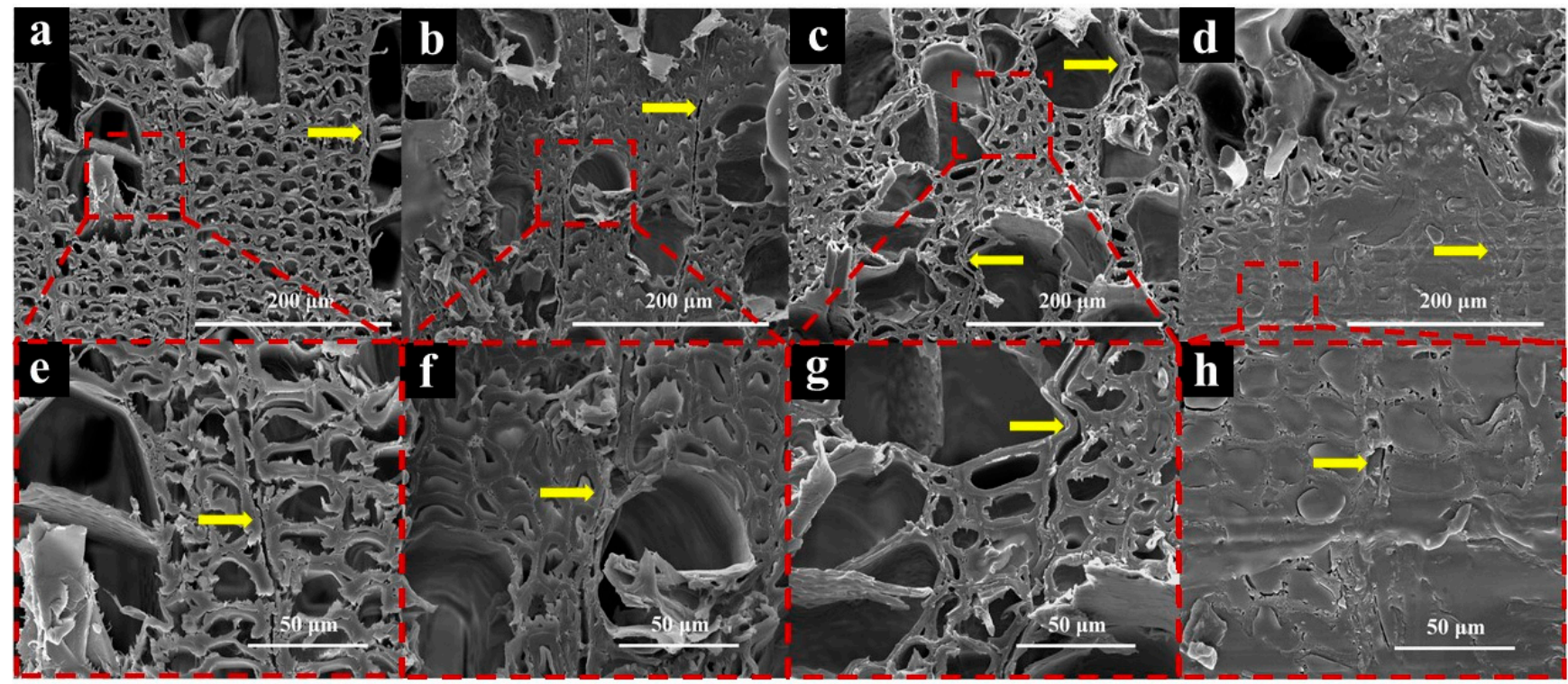

Figure 7. SEM of RV, RV-MP, MV-WS, and MV-OS (a,e-RV, $\mathbf{b}, \mathbf{f}-\mathrm{RV}-\mathrm{MP} . \mathbf{c}, \mathbf{g}-\mathrm{MV}-\mathrm{WS}, \mathbf{d}, \mathbf{h}-\mathrm{MV}-\mathrm{OS})$.

\subsection{XRD Analysis}

Figure 8 shows that RV, RV-MP, and MV-OS had diffraction peaks around $17.0^{\circ}, 22.2^{\circ}$ and $35.0^{\circ}$, corresponding to the wood cellulose (101), (002), and (040) crystal faces [29]. The diffraction peak positions of RV, RV-MP, and MV-OS did not shift, indicating that the microwave and immersion treatment did not destroy the structure of the crystalline wood area. The Segal method was used to calculate the relative crystallinity of RV, RV-MP, and MV-OS, which were 35.84, 36.07, and 38.68, respectively. Compared with RV-MP, the crystallinity of MV-OS increased by $7.24 \%$. The microwave could cause this accelerated moisture evaporation inside the veneer, causing several macromolecular chains in the amorphous region of cellulose to orient towards new crystalline regions [30]. Besides, the abovementioned change in tensile strength also conformed to the general law that the tensile strength of the fiber will increase along with the crystallinity.

\subsection{FT-IR Analysis}

As shown in Figure 9, there was no apparent difference in the RV, RV-MP, and MV-OS spectra and no new characteristic absorption peaks. In other words, the primary stretching vibrations of the spectrum were similar. The characteristic absorption peaks included the -OH stretching vibration in cellulose, $\mathrm{C}-\mathrm{H}$ stretching vibration, acetyl site of hemicellulose, stretching vibration of an aromatic skeleton group of lignin, $\mathrm{C}=\mathrm{O}$ stretching vibration in cellulose, and out-of-plane deformation vibration of benzene ring C-H around $3415 \mathrm{~cm}^{-1}$, $2915 \mathrm{~cm}^{-1}, 1740 \mathrm{~cm}^{-1}, 1505 \mathrm{~cm}^{-1}, 1050 \mathrm{~cm}^{-1}$, and $615 \mathrm{~cm}^{-1}$, respectively [31-33].

Compared with RV-MP, the characteristic absorption peaks of MV-OS, corresponding to the $-\mathrm{OH}$ stretching vibration, $\mathrm{C}=\mathrm{O}$ stretching vibration in cellulose, and out-of-plane deformation vibration of benzene ring $\mathrm{C}-\mathrm{H}$ were greatly enhanced. It can be inferred that the $-\mathrm{OH}$ in the graphene oxide structure was hydrogen-bonded with the - $\mathrm{OH}$ in the wood structure and that $-\mathrm{COOH}$ in the graphene oxide structure was chemically bonded [34]. Besides, the $-\mathrm{COOH}$ on the benzene ring structure of graphene was chemically bonded to 
the free state $-\mathrm{OH}$ in veneer [35]. Additionally, MV-OS was slightly stronger than RV-MP in other characteristic peaks of oxygen-containing functional groups. Thus, this analysis revealed that microwave treatment could establish more space for the graphene oxide to enter. As a result, graphene oxide combined with more $-\mathrm{OH}$ in the poplar veneer during distribution along the pipeline.

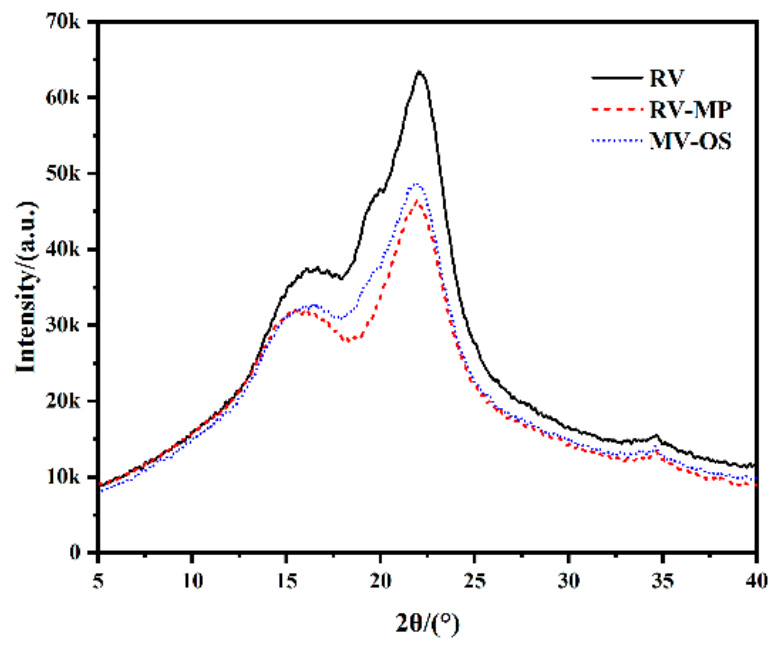

Figure 8. XRD of RV, RV-MP and MV-OS.

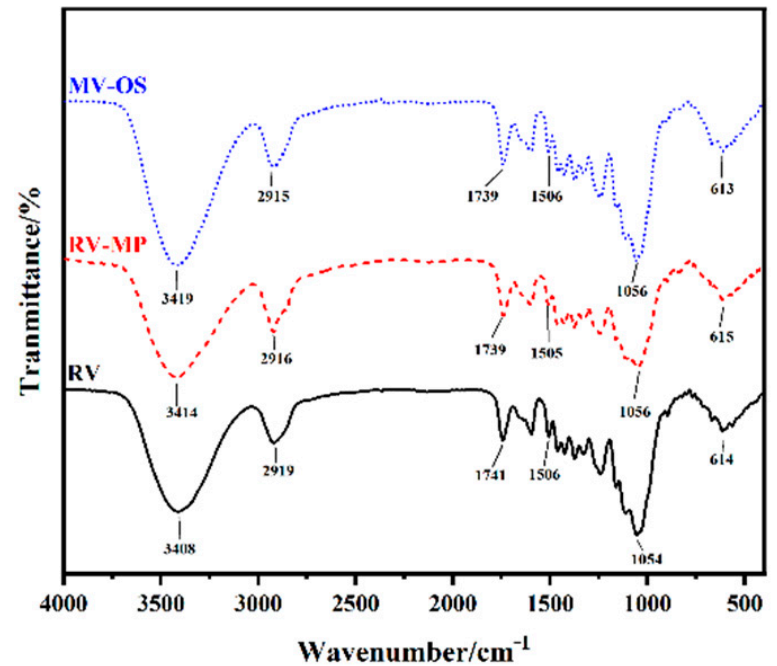

Figure 9. FT-IR spectra of RV, RV-MP, and MV-OS.

\section{Conclusions}

To promote the application of graphene-modified veneers in low-temperature thermal radiation floors, it is important to improve the impregnation effect. Microwave treatment is a standard wood treatment method. It has a great potential when applied to exploring the feasibility of using low-energy-density to improve the impregnation effect of graphene steeping solution. The major conclusions of this study are as follows:

- Microwave treatment improved the impregnation effect of the MV-MP. Compared with untreated veneer and MG/PVA impregnated veneer without microwave treatment, the mechanical properties and thermal conductivity were mostly improved. In this study, the optimal condition was $100 \%$ power microwave processing for $50 \mathrm{~s}$.

- Microwave treatment created more space inside the veneer, thus the MG/PVA steeping solution could enter, impacting the wood rays' thin-walled cells. Nevertheless, this is mainly dependent on the appropriate choice of microwave power and time. 
- $\quad$ Even though microwave treatment affected the wood rays, it had no pronounced effect on its mechanical properties and crystallinity. Besides, the increase in oxygencontaining functional groups, as shown in the FT-IR results, might provide an auxiliary means to prove the existence of graphene oxide.

- Compared with the previous work, it is conjectured that the morphology of graphene impacted the properties of the modified veneers. In addition, we controlled the initial moisture content at first; however, the moisture content is one of the essential factors influencing microwave treatment. These points are both worthy of further discussion in the future.

Author Contributions: Conceptualization, W.X.; methodology, S.W.; software, S.W.; validation, W.X. and S.W.; formal analysis, S.W.; investigation, S.W.; resources, W.X. and S.W.; data curation, S.W.; writing —original draft preparation, S.W.; writing-review and editing, W.X. and S.W. All authors have read and agreed to the published version of the manuscript.

Funding: This research was funded by the Postgraduate Research \& Practice Innovation Program of Jiangsu Province (KYCX21_0904).

Institutional Review Board Statement: Not applicable.

Informed Consent Statement: Not applicable.

Data Availability Statement: The data presented in this study are available on request from the corresponding author.

Acknowledgments: The authors thank the College of Furnishings and Industrial Design of Nanjing Forestry University for supplying laboratories and equipment for this experiment.

Conflicts of Interest: The authors declare no conflict of interest.

\section{References}

1. Yu, Z.T.; Xu, X.; Fan, L.W.; Hu, Y.C.; Cen, K.F. Experimental measurements of thermal conductivity of wood species in China: Effects of density, temperature, and moisture content. For. Prod. J. 2011, 61, 130-135. [CrossRef]

2. Mvondo, R.R.N.; Lissouck, R.O.; Bell, S.; Meukam, P. Investigation on mechanical and thermal properties related to hygroscopicity of two African hardwoods. Wood Mater. Sci. Eng. 2021, 8, 1-12. [CrossRef]

3. Wu, J.; Wang, L.; Shan, X.F.; Wang, X.M. Preparation of 3D-W/rGO conductive materials by hot-press reduction method. J. For. Eng. 2021, 6, 84-93.

4. Lin, X.X.; Jia, S.F.; Liu, J.Y.; Wang, W.B.; Cao, H.M.; Guo, X.; Sun, W.S. Fabrication of thermal energy storage wood based on graphene aerogel encapsulated polyethylene glycol as phase change material. Mater. Res. Exp. 2020, 7, 095503. [CrossRef]

5. Zhang, X.L.; Zhang, J.L.; Wang, R.H. Thermal and mechanical behavior of wood plastic composites by addition of graphene nanoplatelets. Polymers 2019, 11, 1365. [CrossRef]

6. Hsiao, M.C.; Liao, S.H.; Yen, M.Y.; Liu, P.I.; Pu, N.W.; Wang, C.A.; Ma, C.C.M. Preparation of covalently functionalized graphene using residual oxygen-containing functional groups. ACS Appl. Mater. Interface 2010, 2, 3092-3099. [CrossRef]

7. Xu, L.Q.; Yee, Y.K.; Neoh, K.G. Cyclodextrin-functionalized graphene nanosheets, and their host-guest polymer nanohybrids. Polymer 2013, 54, 2264-2271. [CrossRef]

8. Rao, A.N.S.; Nagarajappa, G.B.; Nair, S.; Chathoth, A.M.; Pandey, K.K. Flexible transparent wood prepared from poplar veneer and polyvinyl alcohol. Compos. Sci. Technol. 2019, 182, 107719.

9. Salavagione, H.J.; Gómez, M.A.; Martinez, G. Polymeric modification of graphene through esterification of graphite oxide and poly(vinyl alcohol). Macromolecules 2009, 42, 6331-6334. [CrossRef]

10. Balboni, B.M.; Ozarska, B.; Garcia, J.N.; Torgovnikov, G. Microwave treatment of Eucalyptus macrorhyncha timber for reducing drying defects and its impact on physical and mechanical wood properties. Eur. J. Wood Wood Prod. 2017, 76, 861-870. [CrossRef]

11. Torgovnikov, G.; Vinden, P. Microwave wood modification technology and its application. For. Prod. J. 2010, 60, 173-182. [CrossRef]

12. Ganguly, S.; Balzano, A.; Petrič, M.; Kržišnik, D.; Tripathi, S.; Žigon, J.; Merela, M. Effects of different energy intensities microwave treatment on heartwood and sapwood microstructures in Norway Spruce. Forests 2021, 12, 598. [CrossRef]

13. Weng, X.; Zhou, Y.D.; Fu, Z.Y.; Gao, X.; Fu, F. Effects of microwave treatment on microstructure of Chinese fir. Forests 2020, 11, 772. [CrossRef]

14. Wu, S.S.; Tao, X.; Xu, W. Thermal conductivity of poplar wood veneer impregnated with graphene/polyvinyl alcohol. Forests 2021, 6, 777. [CrossRef]

15. Wu, M.B.; Huang, S.; Liu, C.; Wu, J.; Agarwal, S.; Greiner, A.; Xu, Z.K. Carboxylated wood-based sponges with underoil superhydrophilicity for deep dehydration of crude oil. J. Mater. Chem. A 2020, 8, 11354-11361. [CrossRef] 
16. Cai, Y.J.; Wu, Y.; Yang, F.; Gan, J.; Wang, Y.J.; Zhang, L.J. Wood sponge reinforced with polyvinyl alcohol for sustainable oil-water separation. ACS OMEGA 2021, 6, 12866-12876. [CrossRef]

17. GB/T 17657-2013; Test Methods of Evaluating the Properties of Wood-Based Panels and Surface Decorated Wood-Based Panel. Standard Press: Beijing, China, 2013.

18. Esteves, B.; Sahin, S.; Ayata, U.; Domingos, I.; Ferreira, J.; Gürleyen, L. Effect of heat treatment on shore-D hardness of some wood species. BioResources 2021, 16, 1482-1495. [CrossRef]

19. ASTM D2240-05; Standard Test Method for Rubber Property-Durometer Hardness. ASTM International: West Conshohocken, PA, USA, 2010.

20. Wang, D.; Peng, L.M.; Zhu, G.Y.; Fu, F.; Zhou, Y.D.; Song, B.Q. Improving the sound absorption capacity of wood by microwave treatment. Bioresources 2014, 9, 7504-7518. [CrossRef]

21. Terziev, N.; Daniel, G.; Torgovnikov, G.; Vinden, P. Effect of microwave treatment on the wood structure of Norway Spruce and Radiata Pine. BioResources 2020, 15, 5616-5626. [CrossRef]

22. Xu, K.; Wang, Y.; Lv, J.X.; Li, X. The effect of microwave pretreatment on the impregnation of poplar wood. Bioresources 2015, 10, 282-289. [CrossRef]

23. Krisdianto, S.; Vinden, P.; Torgovnikov, G. Microwave surface modification of Pinus radiate peeler cores: Technical and cost analyses. For. Prod. J. 2010, 60, 346-352.

24. Bi, X.Q.; Zhang, Y.; Li, P.; Wu, Y.Q.; Yuan, G.M.; Zuo, Y.F. Research progress of poplar impregnation modification and its application in furniture. Mater. Rev. 2022, 21, 1-25.

25. Ramezanpour, M.; Tarmian, A.; Taghiyari, H.R. Improving impregnation properties of fir wood to acid copper chromate (ACC) with microwave pre-treatment. Iforest-Biogeosciences For. 2015, 8, 89-94. [CrossRef]

26. Kumar, S.; Saha, A. Graphene nanoplatelets/organic wood dust hybrid composites: Physical, mechanical and thermal characterization. Iran. Polym. J. 2021, 30, 935-951. [CrossRef]

27. Qian, J.M.; Jin, Z.H.; Wang, J.P. Study on the change process of wood ceramic structure prepared by phenolic resin/wood flour composite material. J. Compos. Mater. 2004, 4, 18-23.

28. Mekhtiev, M.A.; Torgovnikov, G. Method of check analysis of microwave modified wood. Wood Sci. Technol. 2004, 38, 507-519. [CrossRef]

29. Chen, H.Y.; Lang, Q.; Bi, Z.; Miao, X.W.; Li, Y.; Pu, J.W. Impregnation of Poplar Wood (Populus Euramericana) with Methylolurea and Sodium Silicate Sol and Induction of In-Situ Gel Polymerization by Heating. Holzforschung 2014, 68, 45-52. [CrossRef]

30. Song, K.Y.; Li, J. Effect of hydrothermal-microwave softened treatment on longitudinal compressing and bending ash wood. Adv. Mater. Res. 2010, 113, 103-108. [CrossRef]

31. Wu, Y.; Zhou, J.C.; Huang, Q.T.; Yang, F.; Wang, Y.J.; Wang, J. Study on the properties of partially transparent wood under different delignification processed. Polymers 2020, 12, 661. [CrossRef]

32. Yaddanapudi, H.S.; Hickerson, N.; Saini, S.; Tiwari, A. Fabrication and characterization of transparent wood for next generation smart building application. Vacuum 2017, 146, 649-654. [CrossRef]

33. Wu, Y.; Zhou, J.C.; Yang, F.; Wang, Y.J.; Wang, J.; Zhang, J.L. A strong multilayered transparent wood with natural wood color and texture. J. Mater. Sci. 2021, 56, 8000-8013. [CrossRef]

34. Xia, Y.; Ma, C.Y.; Wang, H.M.; Sun, S.N.; Wen, J.L.; Sun, R.C. Multiple analysis and characterization of novel and environmentally friendly feather protein-based wood preservatives. Polymers 2020, 12, 237. [CrossRef] [PubMed]

35. Yan, X.X.; Wang, L.; Qian, X.Y. Effect of high-temperature calcined wheat straw powder after lignin removal on properties of waterborne wood coatings. Coatings 2019, 9, 444. [CrossRef] 